\title{
Temporal co-registration for TROPOMI cloud clearing
}

\author{
I. Genkova ${ }^{1, *}$, J. Robaidek ${ }^{2}$, R. Roebling ${ }^{1}$, M. Sneep ${ }^{1}$, and P. Veefkind ${ }^{1}$ \\ ${ }^{1}$ KNMI (Royal Netherlands Meteorological Institute), De Bilt, The Netherlands \\ ${ }^{2}$ University of Wisconsin, Madison, WI, USA \\ *now at: Career Ready, Utrecht, The Netherlands
}

Correspondence to: I. Genkova (ilianagenkova@gmail.com)

Received: 16 June 2011 - Published in Atmos. Meas. Tech. Discuss.: 7 October 2011

Revised: 4 March 2012 - Accepted: 5 March 2012 - Published: 15 March 2012

\begin{abstract}
The TROPOspheric Monitoring Instrument (TROPOMI) is anticipated to provide high-quality and timely global atmospheric composition information through observations of atmospheric constituents such as ozone, nitrogen dioxide, sulfur dioxide, carbon monoxide, methane, formaldehyde and aerosol properties. The methane and the aerosol retrievals require very precise cloud clearing, which is difficult to achieve at the TROPOMI spatial resolution ( 7 by $7 \mathrm{~km}$ ) and without thermal IR measurements. The TROPOMI carrier - the Sentinel 5 Precursor (S5P), does not include a cloud imager, thus it is planned to fly the S5P mission in a constellation with an instrument yielding an accurate cloud mask. The cloud imagery data will be provided by the US NPOESS Preparatory Project (NPP) mission, which will have the Visible Infrared Imager Radiometer Suite (VIIRS) on board (Scalione, 2004). This paper investigates the temporal co-registration requirements for suitable time differences between the VIIRS measurements of clouds and the TROPOMI methane and aerosol measurements, so that the former could be used for cloud clearing. The temporal co-registration is studied using Meteosat Second Generation (MSG) Spinning Enhanced Visible and Infrared Imager (SEVIRI) data with $15 \mathrm{~min}$ temporal resolution (Veefkind, 2008b), and with data from the Geostationary Operational Environmental Satellite - 10 (GOES-10) having 1 min temporal resolution. The aim is to understand and assess the relation between the amount of allowed cloud contamination and the required time difference between the two satellites' overflights. Quantitative analysis shows that a time difference of approximately $5 \mathrm{~min}$ is sufficient (in most conditions) to use the cloud information from the first instrument for cloud
\end{abstract}

clearing in the retrievals using data from the second instrument. In recent years the A-train constellation demonstrated the benefit of flying satellites in formation. Therefore this study's findings will be useful for designing future Low Earth Orbit (LEO) satellite constellations.

\section{Introduction}

Synergistic use of atmospheric measurements has proven to be a successful approach when measurements from a single instrument are insufficient in retrieving accurately certain atmospheric state variables. The Atmospheric Radiation Measurements (ARM) program offers examples of combining ground-based measurements resulting in better characterization of the atmosphere. The Active Remotely Sensed Clouds Locations (ARSCL) product (Clothiaux, 2000) combines data from active remote sensors, a cloud radar and a Raman lidar, to produce an objective determination of hydrometeor height distributions and estimates of their radar reflectivities, thus providing fundamental information for retrieving cloud microphysical properties and assessing the radiative effects of clouds on climate. The Shortwave Flux Analysis (Long and Ackerman, 2000) uses hemispheric, broadband total- and diffuse-shortwave irradiance measurements to identify clear-sky periods using the known characteristics of typical clear-sky irradiance time series. The "A-train" satellite constellation is the first to illustrate the scientific benefits of near simultaneous observations from space (NASA, 2003). Combining data from multiple satellite instruments allow scientists to gain a better understanding 
of the Earth system. For example, A-Train coordinated measurements from CALIPSO (Cloud-Aerosol Lidar and Infrared Pathfinder Satellite Observation), POLDER (POLarization and Directionality of the Earth's Reflectances), MODIS (MODerate resolution Imaging Spectroradiometer) and OMI (Ozone Monitoring Instrument) help characterize better aerosols and their contribution to the Earth Radiation budget (Burrows et al., 2011). CloudSat's CPR (Cloud Profiling Radar) and CALIPSO's Cloud-Aerosol Lidar with Orthogonal Polarisation (CALIOP) together provide a global cloud vertical distribution survey and help answer the question how cloud layering affect the Earth Radiation Budget.

The launch of the TROPOspheric Monitoring Instrument (TROPOMI) is planed for 2014 on board of the Sentinel 5 Precursor (S5P). It will provide global and high-quality atmospheric composition information for climate and air quality studies. The Level 2 products retrieval algorithms need cloud information on a pixel basis. For most of them the cloud properties derived from TROPOMI's own measurements, such as the $\mathrm{O}_{2}$ A-band measurements, will be sufficient. However, the methane and the aerosol retrievals require very precise cloud clearing, which is difficult to achieve at the TROPOMI spatial resolution $(7 \times 7 \mathrm{~km})$ and without thermal IR measurements. To be able to measure methane in the shortwave region with the required accuracy, cloud information is needed from other wavelength regions. The current payload of the Sentinel 5 precursor does not include a cloud imager and information from the UVN (UV-VIS-NIR) spectrometer is insufficient, thus it is proposed to fly the S5P mission in a constellation with another mission having an instrument that can be used for accurate cloud-clearing (Veefkind, 2008b). The cloud imagery data will be obtained by flying S5P/TROPOMI in constellation with the US NPOESS Preparatory Project (NPP) mission, which will have the Visible Infrared Imager Radiometer Suite (VIIRS) on board. VIIRS will have 22 bands in the VIS and IR spectral ranges, and will deliver data with two spatial resolutions - imagery resolution bands with nominal pixel size $370 \mathrm{~m}$ at nadir, and moderate resolution bands with nominal pixel size $740 \mathrm{~m}$ at nadir. VIIRS will provide constrained pixel growth with scan angle. In the middle of the scan the pixel size will be $\sim 0.7 \times 0.7 \mathrm{~km}$ and at the edge of the scan the pixel size will be $\sim 1.6 \times 1.6 \mathrm{~km}$. The instrument is combining fine spatial resolution with high-accuracy calibration similar or superior to the Advanced Very High Resolution Radiometer (AVHRR).

The relation between the accuracy of methane retrievals and cloud contamination has been addressed quantitatively in the recent past (Sneep, et al., 2011; Noel, 2007). In order to derive temporal co-registration requirements, the time difference between the measurements of the cloud mask and the measurement of methane were first investigated using MSG SEVIRI data. The temporal resolution of the imagery (15 min) is a limitation of the study. Thus the study was also performed using a limited data set of 1 min temporal resolution GOES-10 images, yielding more accurate temporal coregistration requirements. In this document we present the results and findings from both data sets.

Section 2 will describe the approach used to derive the coregistration requirements, and the MSG SEVIRI and GOES10 data sets used to estimate the time differences between TROPOMI and an imager instrument. The findings from the data analysis will be presented and discussed in Sect. 3. Finally, in Sect. 4 we will draw conclusions on how to apply the found co-registration requirements.

\section{Method and dataset}

This study simulates collocated observations from two satellite sensors that measure at different times and investigates the effect of the time difference on the efficiency of using the measurement from the first satellite for cloud clearing in the retrieval using the observations from the second satellite. In order to derive the temporal co-registration requirements for time differences between the measurements of clouds and the TROPOMI methane and aerosol measurements we need sequences/series of images equidistant in time. Such are easily derived from geostationary satellites. MSG SEVIRI data is available every $15 \mathrm{~min}$, and the GOES-10 images we use in this study are available every $1 \mathrm{~min}$. By selecting images with different lag in their registration times, and accounting for the field of view of the instruments flying in formation/tandem it is possible to simulate and study the overflights of two instruments over the same geographical area.

The first measurement at $t_{0}$, from the first overflying satellite instrument, is used for deriving a cloud mask and the second measurement at $t_{1}$, from the second satellite instrument, is for the retrieval of the trace gas. Using this setup we study if the cloud mask derived at $t_{0}$ is still valid in $t_{1}$. Ground pixels are classified in three categories - clear, cloudy and cloud edge. Trace gas retrievals at $t_{1}$ will be performed on all pixels that are cloud-free in $t_{0}$. If the cloud has changed in between $t_{0}$ and $t_{1}$, the pixel may no longer be cloud-free at $t_{1}$, and in this case cloud contamination will occur in the trace gas retrieval at $t_{1}$. The decision tree for determining if the trace gas retrieval will be successful or contaminated is shown in Fig. 1 (Veefkind, 2008a).

For a pixel to be identified as clear we require the pixel and its neighboring pixels to be classified as cloud-free. Therefore, a cloud edge test is introduced - it ensures that the pixels on which trace gas retrieval will be applied do not "suffer" from cloud edge effects. Different edge constraints could be used in North-South and East-West directions. In this temporal co-registration study three edge constraints were used for the cloud mask at $t_{0}$ - for Case $\mathrm{A}-1$ neighbor pixel constraint is required in each direction, for Case $\mathrm{B}-2$ neighbor pixels, and for Case $\mathrm{C}-4$ neighbor pixel in longitude and 2 in latitude are required. One edge pixel constraint is set 


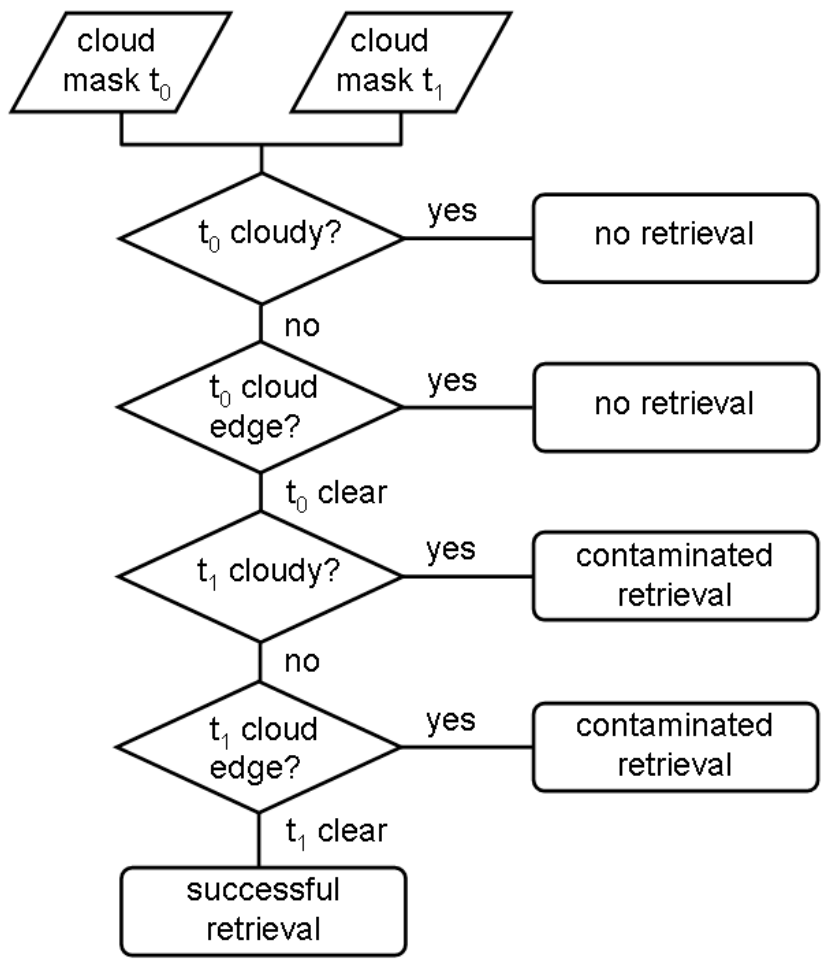

Fig. 1. Decision tree to determine if a trace retrieval will be done at $t_{1}$, and if this retrieval will be successful or cloud contaminated.

for the trace gas retrieval at $t_{1}$ (1 neighbor constraint). This approach is illustrated schematically in Fig. 2.

The first data set we use is 15 min imagery from MSG SEVIRI. The cloud properties retrievals for this data are developed by the EUMETSAT Climate SAF group (Roebeling et al, 2006). The MSG SEVIRI instrument provides an image of the full disk every $15 \mathrm{~min}$ at several wavelengths from the visible to the thermal infrared spectral ranges, from which cloud information is derived. The spatial resolution of SEVIRI is approximately $3 \times 3 \mathrm{~km}^{2}$ at sub-satellite point. Over Europe the ground pixels size increases strongly in the North-South direction due to the curvature of the Earth, which results in resolution of the order of $3 \times 6 \mathrm{~km}^{2}$ over the mid-latitudes. In this study we are using SEVIRI data from year 2006 (6 days from each month), from 11:00 UTC till 15:00 UTC, in the latitude range between $31^{\circ} \mathrm{N}$ and $62^{\circ} \mathrm{N}$, and from $17^{\circ} \mathrm{W}$ to $33^{\circ} \mathrm{E}$. As part of the retrieval described in Roebeling et al. (2006), each SEVIRI ground pixel is categorized as cloud-free, containing water clouds or containing ice clouds. In this study we treat both the ice and water clouds as cloudy pixels.

The second data set used to derive TROPOMI coregistration requirement is one day $(24 \mathrm{~h})$ of data from GOES-10, 23 August 2006, with 1 min temporal resolution. The nominal spatial resolution at nadir is $4 \times 4 \mathrm{~km}^{2}$, however for the latitudes the data is available, $24^{\circ} \mathrm{N}$ to $38^{\circ} \mathrm{N}$, $99^{\circ} \mathrm{W}$ to $84^{\circ} \mathrm{W}$, the ground pixel size is about $4 \times 5 \mathrm{~km}^{2}$.
Normally GOES-10 imagery is available every $30 \mathrm{~min}$, however a limited $1 \mathrm{~min}$ imagery data was collected by UWMadison's Space Science and Engineering Center during the re-positioning of GOES-10 from its operational western location to over Latin and South America (23 August-2 October 2006). During the transition the GOES-10 imager was operated in Super Rapid Scan Operations (SRSO) mode. In this mode, imagery from the satellite is available at oneminute intervals (http://www.ssec.wisc.edu/ rabin/goes10/). Geographical region of the data used in the study is covering Texas, Oklahoma, Tennessee, Arkansas, Louisiana, Mississippi and part of the Gulf of Mexico. About 2/3 of the images are over land and about $1 / 3$ is over ocean. The meteorological conditions captured on 23 August 2006 include some anti-cyclonic activity and convection over Arkansas and Mississippi.

Due to the limited spectral range of GOES-10's channels, the cloud mask developed by the EUMETSAT Climate SAF group and used with MSG SEVIRI data was not possible to apply. Instead, a cloud mask from every image is derived using a bi-spectral composite threshold (BCT) technique utilizing only a thermal infrared and a shortwave infrared spectral chanels (Jedlovec, 2008). The BCT uses the 11 and 3.9 micron channels, and two composite images generated from these channels, in a four-step cloud detection algorithm to produce a binary cloud mask at single pixel resolution. Using composites of the brightness temperature difference imagery to represent the spatially and temporally varying clear sky threshold is a novel aspect of this algorithm. Validation of the algorithm shows it is equally suitable for use during day and night, and over land and ocean (Jedlovec, 2008). An example of the derived cloud mask is shown on Fig. 2.

The BCT cloud mask is simple to implement and not computationally demanding. It requires only two spectral channels, thus it is possible to be applied to MSG SEVIRI data. However, due to the need of composite images the algorithm is not fit for use with subsets of image sequences (i.e. gaps in the data are problematic). The MSG SEVIRI cloud mask is more extensively studied and tested, but it is limited to day time only, and requires data from more channels, thus not applicable to GOES-10. Both cloud masks however could be applied to VIIRS data, and the co-registration requirements could be refined.

\section{Results and discussions}

The impact of the co-registration time difference on the amount of pixels suitable for applying a trace gas retrieval is summarized in Table 1a, b and c for the MSG SEVIRI, and in Table 2a, $\mathrm{b}$ and $\mathrm{c}$ for the GOES-10 data. The statistics are computed for all pixels in the datasets, individually for each of the three cases. A pixel that contains valid data can be classified as: clear, meaning that the trace gas retrieval is assumed valid; cloudy, meaning that no retrieval gas retrieval is 

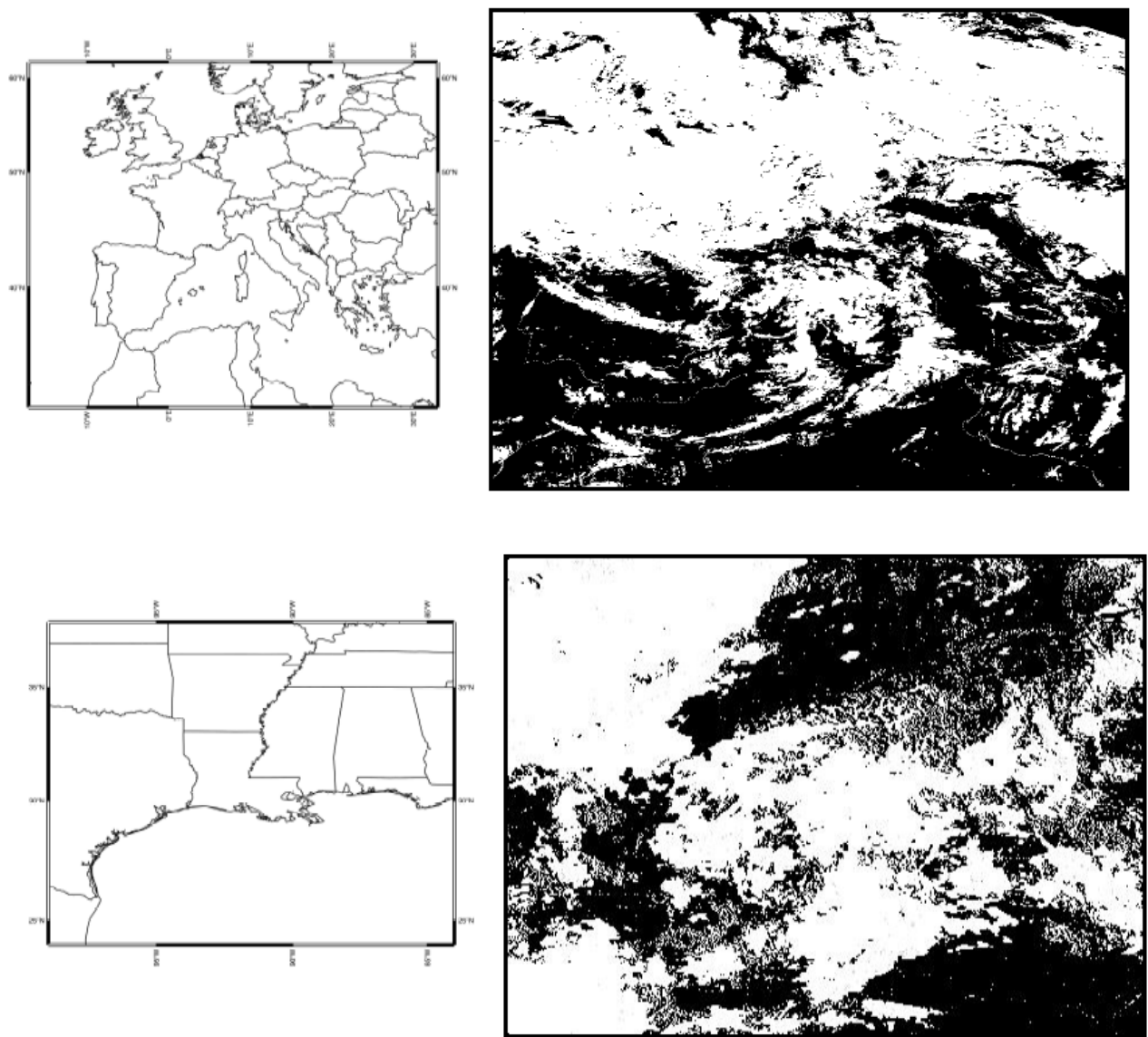

Fig. 2. Example of the cloud classification by: (a) the CM-SAF algorithm and (b) the GOES-10 algorithm. Black pixels are classified as cloud-free and white as clouds.

Table 1a. Statistics for Case A from MSG SEVIRI.

\begin{tabular}{lrrrr}
\hline $\begin{array}{l}t_{i}-t_{0}, \\
{[\mathrm{~min}]}\end{array}$ & $\begin{array}{r}\text { Number } \\
\text { of Pixels }\end{array}$ & $\begin{array}{r}\text { Cloudy } \\
\text { Pixels [\%] }\end{array}$ & $\begin{array}{r}\text { Clear } \\
\text { Pixels [\%] }\end{array}$ & $\begin{array}{r}\text { Cloud } \\
\text { Contami- } \\
\text { nated [\%] }\end{array}$ \\
\hline 15 & $4.37 \mathrm{E}+08$ & 72.31 & 25.18 & 2.516 \\
30 & $4.25 \mathrm{E}+08$ & 71.90 & 24.38 & 3.721 \\
45 & $4.10 \mathrm{E}+08$ & 71.43 & 23.88 & 4.691 \\
60 & $3.95 \mathrm{E}+08$ & 70.98 & 23.46 & 5.561 \\
\hline
\end{tabular}

applied because the pixel or its surrounding pixels are flagged as cloudy; or cloud contaminated, meaning that a retrieval is applied, but the pixel contains cloud or one of its direct neighbors contains a cloud.

The statistics for Case A, B and C are presented in Table $1 \mathrm{a}, \mathrm{b}$ and $\mathrm{c}$ for MSG SEVIRI, and Table $2 \mathrm{a}, \mathrm{b}$, c for GOES-10, respectively. It can be seen that for Case A (for both MSG SEVIRI and GOES-10) approximately $25 \%$ of the pixels in the second image are classified as clear when the time difference is $15 \mathrm{~min}$. This amount of pixels is higher compared to the study by Krijger et al. (2007). It appears
Table 1b. Statistics for Case B from MSG SEVIRI.

\begin{tabular}{lrrrr}
\hline $\begin{array}{l}t_{i}-t_{0}, \\
{[\mathrm{~min}]}\end{array}$ & $\begin{array}{r}\text { Number } \\
\text { of Pixels }\end{array}$ & $\begin{array}{r}\text { Cloudy } \\
\text { Pixels [\%] }\end{array}$ & $\begin{array}{r}\text { Clear } \\
\text { Pixels [\%] }\end{array}$ & $\begin{array}{r}\text { Cloud } \\
\text { Contami- } \\
\text { nated [\%] }\end{array}$ \\
\hline 15 & $4.35 \mathrm{E}+08$ & 77.32 & 21.77 & 0.9051 \\
30 & $4.22 \mathrm{E}+08$ & 76.96 & 21.31 & 1.731 \\
45 & $4.08 \mathrm{E}+08$ & 76.53 & 21.00 & 2.47 \\
60 & $3.93 \mathrm{E}+08$ & 76.12 & 20.71 & 3.167 \\
\hline
\end{tabular}

Table 1c. Statistics for Case C from MSG SEVIRI.

\begin{tabular}{lrrrr}
\hline $\begin{array}{l}t_{i}-t_{0}, \\
{[\mathrm{~min}]}\end{array}$ & $\begin{array}{r}\text { Number } \\
\text { of Pixels }\end{array}$ & $\begin{array}{r}\text { Cloudy } \\
\text { Pixels [\%] }\end{array}$ & $\begin{array}{r}\text { Clear } \\
\text { Pixels [\%] }\end{array}$ & $\begin{array}{r}\text { Cloud } \\
\text { Contami- } \\
\text { nated [\%] }\end{array}$ \\
\hline 15 & $4.33 \mathrm{E}+08$ & 80.22 & 19.31 & 0.4718 \\
30 & $4.20 \mathrm{E}+08$ & 79.88 & 19.09 & 1.038 \\
45 & $4.06 \mathrm{E}+08$ & 79.48 & 18.91 & 1.606 \\
60 & $3.91 \mathrm{E}+08$ & 79.10 & 18.73 & 2.170 \\
\hline
\end{tabular}



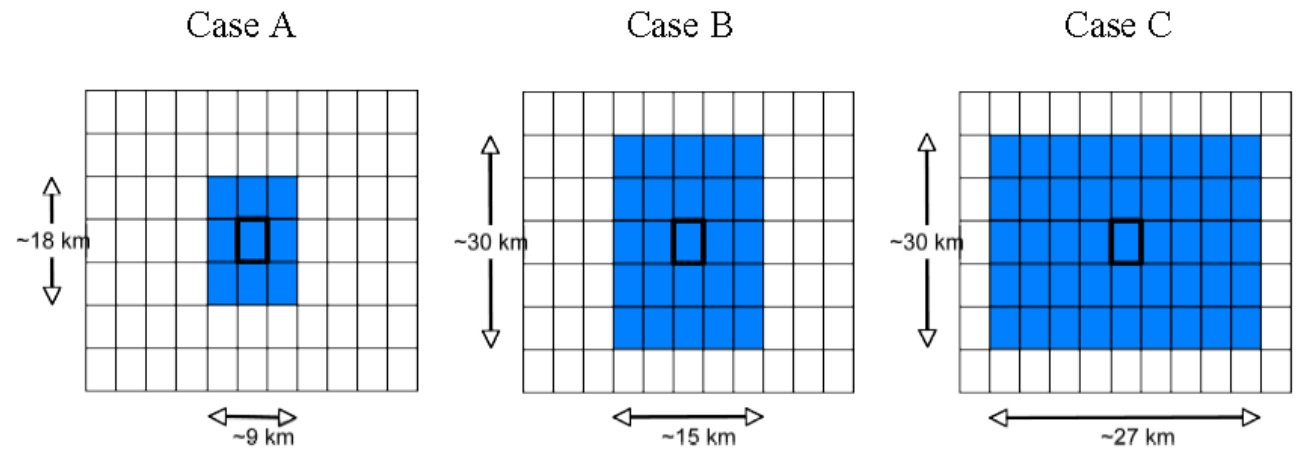

Fig. 3. Schematic of the neighbouring ground pixels included in the edge test. Sizes for the blue areas are given for the MSG SEVIRI data. The pixel that is tested is the centre pixel in each figure. Left figure shows a test with 1 neighbour included in all directions (Case A). The middle figure shows a test with 2 neighbours included in each direction (Case B). The right figure shows a constraint with 4 neighbours in the East-West direction and 2 in the North-South direction (Case C).

Table 2a. Statistics for Case A from GOES-10.

\begin{tabular}{rrrrr}
\hline $\begin{array}{r}t_{i}-t_{0}, \\
{[\mathrm{~min}]}\end{array}$ & $\begin{array}{r}\text { Number } \\
\text { of Pixels }\end{array}$ & $\begin{array}{r}\text { Cloudy } \\
\text { Pixels [\%] }\end{array}$ & $\begin{array}{r}\text { Clear } \\
\text { Pixels [\%] }\end{array}$ & $\begin{array}{r}\text { Cloud } \\
\text { Contami- } \\
\text { nated [\%] }\end{array}$ \\
\hline 0 & 22039290 & 67.87 & 32.12 & 0.00 \\
1 & 20570004 & 68.12 & 31.14 & 0.72 \\
2 & 19310616 & 68.24 & 30.51 & 1.24 \\
3 & 18051228 & 68.35 & 30.00 & 1.64 \\
4 & 16791840 & 68.46 & 29.53 & 1.99 \\
5 & 15532452 & 68.58 & 29.11 & 2.30 \\
6 & 14273064 & 68.69 & 28.70 & 2.60 \\
7 & 13013676 & 68.80 & 28.32 & 2.87 \\
8 & 11754288 & 68.89 & 27.98 & 3.11 \\
9 & 10494900 & 68.98 & 27.69 & 3.31 \\
10 & 9235512 & 69.07 & 27.42 & 3.49 \\
11 & 7976124 & 69.16 & 27.16 & 3.67 \\
12 & 6716736 & 69.22 & 26.94 & 3.82 \\
13 & 6087042 & 69.26 & 26.74 & 3.99 \\
14 & 5457348 & 69.28 & 26.57 & 4.13 \\
15 & 4827654 & 69.29 & 26.43 & 4.26 \\
16 & 4197960 & 69.25 & 26.33 & 4.40 \\
17 & 3568266 & 69.16 & 26.27 & 4.55 \\
18 & 2938572 & 69.12 & 26.23 & 4.64 \\
19 & 2308878 & 68.98 & 26.26 & 4.74 \\
20 & 1679184 & 68.66 & 26.59 & 4.74 \\
\hline & & & &
\end{tabular}

that the cloud mask from SEVERI may be less stringent than the one produced from MODIS. Therefore the number produced in this study should be evaluated in a relative way. The amount of clear pixels for each of the three cases, for the $15 \mathrm{~min}$ time difference, and for both data sets is shown on Fig. 4.

To quantify the effect of the time difference on the number of cloud affected pixels we express the cloud-contaminated pixels as percentage of the pixels for which a trace gas retrieval is assumed valid. The percentage of affected retrievals
Table 2b. Statistics for Case B from GOES-10.

\begin{tabular}{rrrrr}
\hline $\begin{array}{r}t_{i}-t_{0}, \\
{[\mathrm{~min}]}\end{array}$ & $\begin{array}{r}\text { Number } \\
\text { of Pixels }\end{array}$ & $\begin{array}{r}\text { Cloudy } \\
\text { Pixels [\%] }\end{array}$ & $\begin{array}{r}\text { Clear } \\
\text { Pixels [\%] }\end{array}$ & $\begin{array}{r}\text { Cloud } \\
\text { Contami- } \\
\text { nated [\%] }\end{array}$ \\
\hline 0 & 21829500 & 79.27 & 20.72 & 0.00 \\
1 & 20374200 & 79.51 & 20.38 & 0.09 \\
2 & 19126800 & 79.63 & 20.19 & 0.16 \\
3 & 17879400 & 79.74 & 20.01 & 0.23 \\
4 & 16632000 & 79.84 & 19.83 & 0.31 \\
5 & 15384600 & 79.95 & 19.66 & 0.37 \\
6 & 14137200 & 80.04 & 19.49 & 0.45 \\
7 & 12889800 & 80.13 & 19.33 & 0.52 \\
8 & 11642400 & 80.21 & 19.18 & 0.59 \\
9 & 10395000 & 80.28 & 19.05 & 0.66 \\
10 & 9147600 & 80.34 & 18.92 & 0.72 \\
11 & 7900200 & 80.38 & 18.81 & 0.79 \\
12 & 6652800 & 80.39 & 18.73 & 0.87 \\
13 & 6029100 & 80.40 & 18.65 & 0.94 \\
14 & 5405400 & 80.39 & 18.58 & 1.01 \\
15 & 4781700 & 80.37 & 18.54 & 1.07 \\
16 & 4158000 & 80.31 & 18.54 & 1.14 \\
17 & 3534300 & 80.19 & 18.58 & 1.21 \\
18 & 2910600 & 80.07 & 18.64 & 1.27 \\
19 & 2286900 & 79.83 & 18.82 & 1.33 \\
20 & 1663200 & 79.33 & 19.30 & 1.36 \\
\hline & & & &
\end{tabular}

is calculated as:

Percentage affected pixels $=$

$=100 *($ cloud contaminated pixels $] /[$ [clear pixels]

+ [cloud contaminated pixels] $])$.

The percentage of affected retrievals as a function of the time difference between $t_{0}$ and $t_{1}$ for Case $\mathrm{A}, \mathrm{B}$ and $\mathrm{C}$ is shown in Fig. 5. The curves in this figure are drawn through the origin, as the number of affected pixels at 0 time difference is per definition 0 . As expected, the percentage of affected pixels increases with increasing time difference. Also, the 
Table 2c. Statistics for Case C from GOES-10.

\begin{tabular}{rrrrr}
\hline $\begin{array}{r}t_{i}-t_{0}, \\
{[\mathrm{~min}]}\end{array}$ & $\begin{array}{r}\text { Number } \\
\text { of Pixels }\end{array}$ & $\begin{array}{r}\text { Cloudy } \\
\text { Pixels [\%] }\end{array}$ & $\begin{array}{r}\text { Clear } \\
\text { Pixels [\%] }\end{array}$ & $\begin{array}{r}\text { Cloud } \\
\text { Contami- } \\
\text { nated [\%] }\end{array}$ \\
\hline 0 & 21704760 & 84.58 & 15.41 & 0.00 \\
1 & 20257776 & 84.79 & 15.16 & 0.04 \\
2 & 19017504 & 84.89 & 15.02 & 0.07 \\
3 & 17777232 & 84.99 & 14.90 & 0.10 \\
4 & 16536960 & 85.08 & 14.78 & 0.12 \\
5 & 15296688 & 85.17 & 14.68 & 0.14 \\
6 & 14056416 & 85.25 & 14.57 & 0.16 \\
7 & 12816144 & 85.33 & 14.48 & 0.18 \\
8 & 11575872 & 85.39 & 14.39 & 0.21 \\
9 & 10335600 & 85.45 & 14.31 & 0.23 \\
10 & 9095328 & 85.49 & 14.25 & 0.25 \\
11 & 7855056 & 85.51 & 14.19 & 0.28 \\
12 & 6614784 & 85.50 & 14.18 & 0.31 \\
13 & 5994648 & 85.49 & 14.14 & 0.35 \\
14 & 5374512 & 85.48 & 14.13 & 0.38 \\
15 & 4754376 & 85.45 & 14.12 & 0.41 \\
16 & 4134240 & 85.38 & 14.16 & 0.45 \\
17 & 3514104 & 85.27 & 14.24 & 0.48 \\
18 & 2893968 & 85.12 & 14.35 & 0.51 \\
19 & 2273832 & 84.86 & 14.58 & 0.54 \\
20 & 1653696 & 84.33 & 15.10 & 0.56 \\
\hline
\end{tabular}

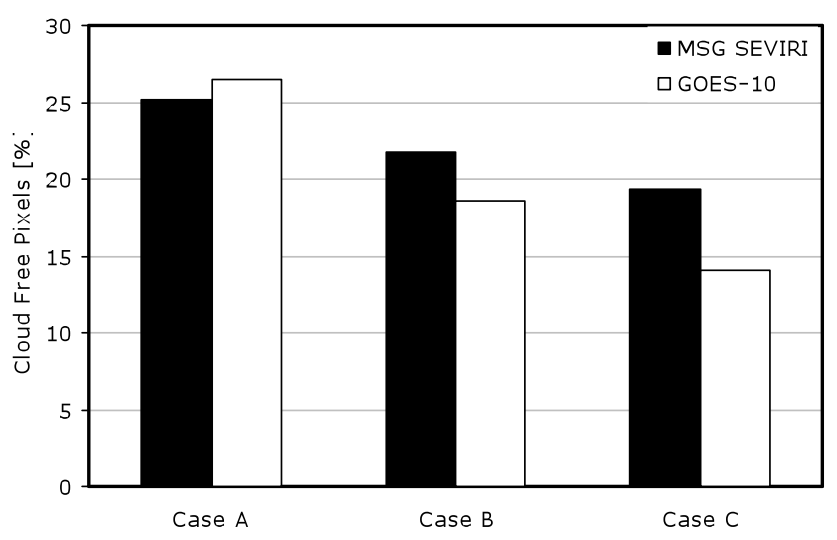

Fig. 4. Percentage of cloud free pixels for Case A, B, and C.

percentage decreases with increasing the size of the retrieval footprint, i.e. from Case A to Case C.

If we apply an arbitrary threshold value for the percentage of affected pixels of $2 \%$, the time differences derived from Fig. 5 range from less than $5 \mathrm{~min}$ for Case A to $15 \mathrm{~min}$ for Case $\mathrm{C}$ for MSG SEVIRI. For GOES-10, the time differences are $1 \mathrm{~min}$ for Case A and $10 \mathrm{~min}$ for Case $\mathrm{C}$.

For a $1 \%$ threshold the time differences for MSG SEVIRI range from $1 \mathrm{~min}$ for Case $\mathrm{A}$ to $7 \mathrm{~min}$ for Case $\mathrm{C}$, and for the GOES-10 data set the range is from $0.5 \mathrm{~min}$ for Case A to 5 min for Case C.

Using GOES-10 1 min imagery allows complementing the results from the study using MSG SEVIRI data by look-

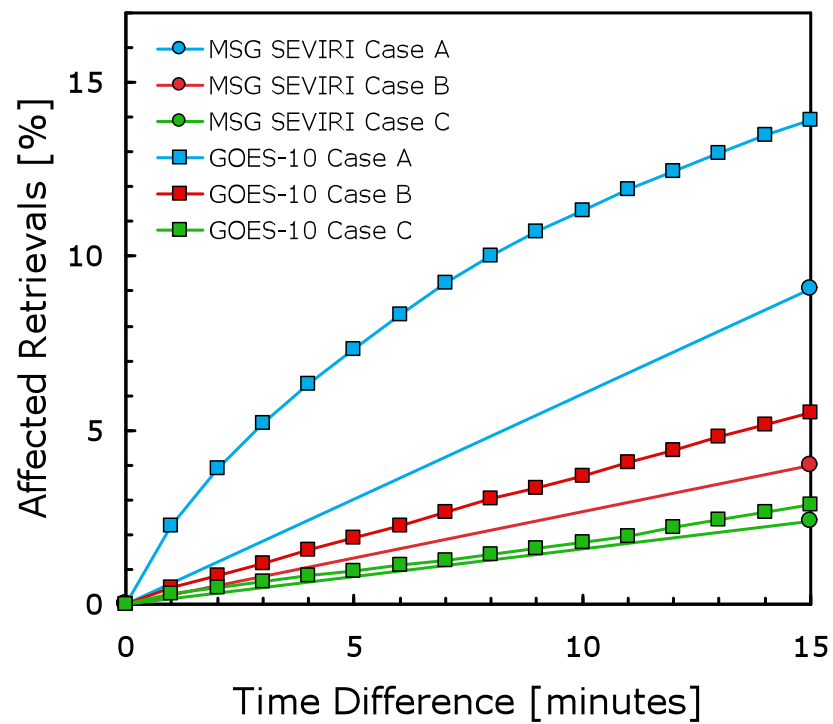

Fig. 5. Percentage of affected trace gas retrievals as function of the time difference between $t_{0}$ and $t_{1}$ for Case A (blue), B (red) and C (green) for the study using 15 min MSG SEVRI data (marked with filled circles) and for the study using $1 \mathrm{~min}$ GOES-10 data (marked with black crosses).

ing into time differences $t_{0}-t_{1}$ smaller than $15 \mathrm{~min}$. The temporal co-registration requirements can be defined more precisely instead of using linear interpolation between 0 and $15 \mathrm{~min}$, as it was done for the MSG data. However, we note that the MSG SEVIRI data set is significantly larger, data coverage is different and it includes a range of meteorological situations. Nevertheless, the limited GOES-10 data set allows us to study time differences ranging from 0 to $20 \mathrm{~min}$, thus comparing the results from both data sets for the $15 \mathrm{~min}$ time difference.

The constraints for cloud free pixels are stronger for Case $\mathrm{B}$ and $\mathrm{C}$ as compared to Case A. Therefore the number of cloud free pixels is lower for Case B and C, as can be seen in Table 1. The percentage of clear pixels for each case is graphically displayed in Fig. 4. The figure shows that for the MSG SEVIRI data the percentage of cloud free pixels decreases with approximately $5 \%$ from Case A to Case C. In a relative way, the decrease from Case $\mathrm{A}$ to Case $\mathrm{C}$ is $24 \%$. For the GOES-10 data sets the reduction of cloud free pixels from Case A to Case $\mathrm{C}$ is twice as large. Note that for a clear pixel the area without clouds is 5 times larger for Case C compared to Case A, as can be seen in Fig. 3. In the MODIS study by Krijger et al. (2007) it was found that going from pixels with an area $9 \times 18 \mathrm{~km}^{2}$ to $27 \times 30 \mathrm{~km}^{2}$ resulted in a decrease of clear pixels of $43 \%$, which is significantly larger than the $24 \%$ found in this study. It is noted that the cloud edge test is different from the cloud test performed by Krijger et al. (2007) but the difference in decrease of clear pixels may also be the result of the different cloud clearing schemes. 
Figure 5 illustrates the amount of Affected Pixels as a function of the time lag between the cloud mask and the trace gas retrieval, i.e. the time difference between $t_{0}$ and $t_{1}$ from the MSG SEVIRI and GOES-10 studies. The percentage of affected pixels increases with the increasing time difference for all cases. Also, the percentage decreases from Case A to Case C. The same trends were observed in the study using MSG SEVIRI data.

The more restrictive co-registration requirements may be explained with more sensitive GOES-10 Cloud Mask and because of the differences in the cloud scenes and spatial coverage from the MSG SEVIRI study and the linear approximation connecting the 0 and $15 \mathrm{~min}$ time difference for the MSG curves on Fig. 5.

Figure 5 also shows largest differences between the MSG SEVIRI and GOES-10 results are observed for Case A. Case A has 1 neighbor pixel constraint and not much smoothing effects could take place. For Cases B and C, the larger the area, the higher the chance of change in cloud presence and morphology, thus the results from MSG SEVIRI and GOES10 are more similar.

\section{Conclusions and perspectives}

This paper presents the results from a study assessing the cloud contamination as a function of the time difference between the cloud mask measurement and the trace gas measurement using MSG SEVIRI and GOES-10 data. It has been performed for the TROPOMI/Sentinel 5 Precursor measurements of methane, for which cloud information from another satellite may be used. However, the approach could be adapted with success for other LEO satellite constellation missions, when synergistic use of data is anticipated.

The analysis of MSG SEVIRI and GOES-10 data shows that if only $2 \%$ of the retrievals are allowed to contain cloud contamination, the derived time difference between the satellites (for Case A) should be from less than 15 min to less than $5 \mathrm{~min}$, depending on the data set respectively. If only $1 \%$ cloud contamination is allowed the time difference ranges from 7 to $1 \mathrm{~min}$. The reported range is determined by the use of two data sets, analyzed with different cloud mask, and with varying constraints for the detection of cloud edges. When the constraints are stronger, the number of affected pixels decreases and the allowed time difference becomes larger. However, stronger constraints also result in less pixels passing the cloud tests and possibly marking clear pixels as cloudy. From the weakest to the strongest constraints used in this study, the number of clear pixels decreased by $20 \%$. A recent study using MODIS data reported a $43 \%$ decrease with increasing region of interest (Krijger, 2007). This difference is rather large and could be further investigated.

The results in this study are limited to MSG SEVIRI data over Europe and GOES-10 data over parts of USA, which have a typical spatial resolution of 3 by $6 \mathrm{~km}$ and 4 by $5 \mathrm{~km}$, respectively. The Sentinel 5 Precursor SWIR measurements are expected to have a spatial resolution of better than 10 by $10 \mathrm{~km}$ at nadir, and the cloud mask from for example VIIRS on NPOESS less than 1 by $1 \mathrm{~km}$.

As studies in the past have shown (Genkova, 2007; Zhao, 2007; Menzel, 2008) the cloud properties retrievals and climatologies are strongly dependent on the spatial resolution of the sensor and the data. The improved spatial resolution of the cloud mask will strongly increase the amount of information on clouds. It is expected that this information can be used to optimize the cloud clearing procedure, thus reducing the cloud contamination. It would be valuable to adapt and apply the here presented approach to VIIRS data when it becomes available and before the TROPOMI launch. Such new results could be used to assess the amount of pixels for which a trace gas retrieval will be impacted due to temporal co-registration limitation.

Acknowledgements. Iliana Genkova would like to thank Tom Whittaker for his help with the handling of the AREA data, Patricia Castellanos for the maps in Fig. 2, Leslie Moy for proofreading the paper and Erik Pragt for his contagious work enthusiasm.

Edited by: M. Van Roozendael

\section{References}

Burrows, J. P., Platt, U., and Borrell, P. (Eds.): The Remote Sensing of Tropospheric Composition from Space, Springer, UK, 2011.

Clothiaux, E., Ackerman, T. P., Mace, J., Moran, K., Marchand, R., Miller, M., and Martner, B.: Objective Determination of Cloud Heights and Radar Reflectivities Using a Combination of Active Remote Sensors at the ARM CART Sites, J. Appl. Meteorol., 39, 645-665, 2000.

Genkova, I., Seiz, G., Zuidema, P., Zhao, G., and Di Girolamo, L.: Cloud Top Height Comparisons from ASTER, MISR, and MODIS for Trade Wind Cumuli, Remote Sens. Environ., 107, 211-222, 2007.

Jedlovec, G. J., Haines, S. L., and LaFontaine, F. J.: Spatial and Temporal Varying Thresholds for Cloud Detection in GOES Satellite Imagery, IEEE T. Geosci. Remote, 46, 1705-1717, 2008.

Krijger, J. M., van Weele, M., Aben, I., and Frey, R.: Technical Note: The effect of sensor resolution on the number of cloud-free observations from space, Atmos. Chem. Phys., 7, 2881-2891, doi:10.5194/acp-7-2881-2007, 2007.

Long, C. N. and Ackerman, T. P.: Identification of Clear Skies from Broadband Pyranometer Measurements and Calculation of Downwelling Shortwave Cloud Effects, J. Geophys. Res, 105, 15609-15626, 2000.

Menzel, W. P., Frey, R., Zhang, H., Wylie, D., Moeller, C., Holz, R., Maddux, B., Baum, B., Strabala, K., and Gumley, L.: MODIS global cloud-top pressure and amount estimation: Algorithm description and results, J. Appl. Meteorol. Clim., 47, 1175-1198, 2008.

NASA Goddard Space Flight Center, Formation Flying: The Afternoon "A-Train" Satellite Constellation, Article FS-2003-1-053GSFC, 2003. 
Noel, S.: Description of the AMC-DOAS algorithm, IFE-TNAMCDOAS-001, 21 August 2007.

Roebeling, R. A., Feijt, A. J., and Stammes, P.: Cloud property retrievals for climate monitoring: Implications of differences between Spinning Enhanced Visible and Infrared Imager (SEVIRI) on METEOSAT-8 and Advanced Very High Resolution Radiometer (AVHRR) on NOAA-17, J. Geophys. Res., 111, D20210, doi:10.1029/2005JD006990, 2006.

Scalione, T., Swenson, H. W., De Luccia, F., Schueler, C., Clement, J. E., and Darnton, L.: Post-CDR NPOESS VIIRS sensor design and performance, Proc. SPIE Int. Soc. Opt. Eng., 5234, 144155, 2004.
Sneep, M., de Haan, J., and Veefkind, P.: Cloud retrieval using the oxygen A-band in support of trace gas retrievals from TROPOMI, European Geosciences Union General Assembly, Vienna, Austria, 3-8 April 2011.

Veefkind, J. P.: Temporal Co-registration for Cloud Clearing Tech. Note TN-CAM-KNMI-036, 2008a

Veefkind, J. P.: Orbit possibilities for the Sentinel 5 Precursor, CAMELOT Tech. Note TN-CAM-KNMI-019, 2008 b.

Zhao, G. and Di Girolamo, L.: Statistics on the macrophysical properties of trade wind cumuli over the tropical western Atlantic, J. Geophys. Res., 112, L20814, doi:10.1029/2006JD007371, 2007. 